\title{
Complete Large-Molecule High-Resolution Mass Spectra from 50-Femtomole Microvolume Injection
}

\author{
Neil L. Kelleher, Michael W. Senko, Daniel P. Little, Peter B. O'Connor, \\ and Fred W. McLafferty \\ Department of Chemistry, Cornell University, Ithaca, New York, USA
}

For electrospray ionization in Fourier-transform mass spectrometry, direct injection of $5 \times$ $10^{-14} \mathrm{~mol}(0.5 \mu \mathrm{L}$ of $100 \mathrm{nM}$ from a microvolume sample valve) of ubiquitin (8565 Da) into the flowing solvent stream yields a spectrum with 85:1 signal-to-noise ratio, 2-ppm mass accuracy, and isotopic resolution. Gated trapping for $100 \mu \mathrm{s}$ from a $0.15-\mu \mathrm{L} / \mathrm{min}$ injection of $20-\mu \mathrm{M}$ ubiquitin consumes $5 \times 10^{-18} \mathrm{~mol}$, which produces a spectrum with 23:1 signal-tonoise ratio and $>3 \times 10^{5}$ resolving power. (J Am Soc Mass Spectrom 1995, 6, 220-221)

$\mathrm{M}$ atrix-assisted laser desorption (MALDI) [1] and electrospray ionization (ESI) [2] have revolutionized mass spectrometry of molecules larger than $5 \mathrm{kDa}$ [3]. Minimizing detection limits is especially critical for biomedical applications; spectra recorded by using MALDI [4] and ESI [5-10] have been reported over a wide mass range on $10^{-17}$ and $10^{-13}-10^{-18} \mathrm{~mol}$, respectively, of total sample brought to the instrument. MALDI only requires laser focusing on this amount of solid sample, and the time-of-flight instrument records the full spectrum. However, solution introduction by ESI has demanded continuous sample spraying for many seconds (actually a necessity for full spectra from the scanning instruments usually employed [5-10]). Recently, subfemtomole sample consumption also has been achieved with intermittent microcapillary ESI of microvolume samples $[5,9,10]$ and with capillary electrophoresis (CE) [6] and liquid chromatographic (LC) [7] electrospray ionization-mass spectrometry (ESI/MS) coupling that limit ion introduction times to a chromatographic peak width [11]. Hofstadler et al. [12] have used a CE interface to introduce low femtomole amounts of proteins into a Fourier-transform (FT) mass spectrometer to provide complete spectra at unit resolution. As a simple alternative, we describe here high resolution FT mass spectra obtained by $10^{-14}$-mol sample introduction with a commercial microvolume injector.

A mobile phase of 78:20:2 MeOH: $\mathrm{H}_{2} \mathrm{O}: \mathrm{HOAc}$ was infused at $1 \mu \mathrm{L} / \mathrm{min}$ with a Harvard syringe pump 22 (South Natick, MA) into the ESI system through a four-port 7413 injector (Rheodyne, Cotati, CA). Its 0.5$\mu \mathrm{L}$ internal sample loop ports were modified to accept deactivated fused silica capillary tubing $(0.10-\mathrm{mm}$

Address communications to F. W. McLafferty, Baker Chemistry Laboratory, Cornell University, Ithaca, NY 14853-1301. i.d. $\times 0.22-\mathrm{mm}$ o.d.) with stainless steel metal guides (1.6-mm o.d. $\times 0.25-\mathrm{mm}$ i.d.) to fill port dead volumes. The capillary tubing $(60 \mathrm{~mm})$ was connected with a mini union $(0.30-\mathrm{mm}$ i.d.) to the ESI spray needle, which was mounted on the injector with a Teflon support. Efficient sample loading (i.e., negligible dead volume) into the $0.5-\mu \mathrm{L}$ loop utilized a $10-\mu \mathrm{L}$ high performance liquid chromatography syringe (Scientific Instrument Services, Ringoes, NJ) with a blunt tip that matched the inner diameter of the guide tube in the $1.6-\mathrm{mm}$ loading port. Electrosprayed ions were directed through five stages of differential pumping into a cylindrical trapped ion cell at $\sim 10^{-9}$ torr of a modified 6-T Extrel 2000 series Fourier transform mass spectrometer (FTMS), described elsewhere [13].

After a steady spray was established, injection of 10-pmol $(0.5 \mu \mathrm{L}$ of $20 \mu \mathrm{M})$ ubiquitin (Sigma) dissolved in the mobile phase produced the Figure 1 profile of ion current recorded with a collector positioned beyond the cell. Peak current from the same sample solution with continuous flow was $200 \mathrm{pA}$, which is consistent with the $\sim 50 \%$ dilution indicated by the Figure 1 peak broadening [10] versus the $30 \mathrm{~s}$ expected for undiluted transfer $(0.5 \mu \mathrm{L}$ at $1 \mu \mathrm{L} / \mathrm{min})$. The 15-20-pA background was due to solvent clusters larger than the $m / z \sim 60$ cutoff of the rf-only quadrupoles.

After reduction of the sample concentration (which should also exacerbate band broadening), $50 \mathrm{fmol}(0.5$ $\mu \mathrm{L}$ of $100 \mathrm{nM}$ ) of ubiquitin was injected and ions were accumulated for a total of $6 \mathrm{~s}\left(4 \mathrm{~s}\right.$ at $6 \times 10^{-6}$ torr argon and $2 \mathrm{~s}$ as base pressure was restored) at a delay time that corresponds to maximum ion current. The resulting spectrum (Figure 2; data collection time $1 \mathrm{~s}$ ) shows signal-to-noise ratio $(\mathrm{S} / \mathrm{N})$ of $85: 1$, resolving power (RP) of $4 \times 10^{4}$, and a weighted average mass 


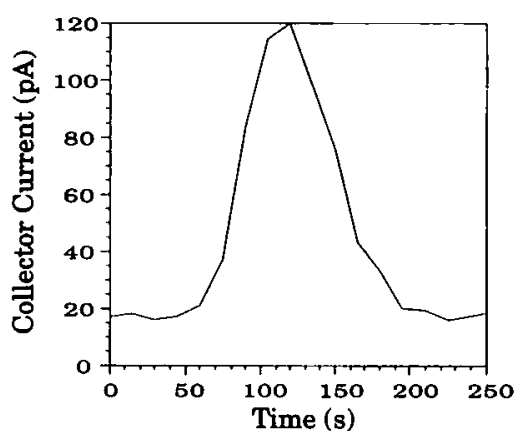

Figure 1. Ion current versus time profile for $0.5-\mu \mathrm{L}$ loop injection of $20-\mu \mathrm{M}$ ubiquitin into the solvent stream flowing at 1 $\mu \mathrm{L} / \mathrm{min}$. Constant infusion of the same solution yielded 200-pA ion current.

for the most abundant isotope peak of the six charge states of $8564.66 \mathrm{Da}$ (external calibration) versus the theoretical value of $8564.64 \mathrm{Da}$. Note that impurity peaks an order of magnitude lower in mass are clearly visible, which illustrates the unique multichannel recording at high resolution possible with FTMS. Injecting $10 \mathrm{fmol}(0.5 \mu \mathrm{L}$ of $20 \mathrm{nM})$ gave unit resolution for the $10^{+}$charge state (not shown), but only $3: 1 \mathrm{~S} / \mathrm{N}$, which indicates this is the band-broadening limit with this apparatus.

By minimizing sample dilution (a smaller capillary with plug flow; no dead volume), a much smaller injector volume should be feasible. This lower limit was estimated by a gated trapping experiment that involved sequentially raising the trapping voltages of the ion cell during ion introduction, with the back trap plate pulsed high $100 \mu \mathrm{s}$ before the front to trap ions before axial loss. Ions were generated from $20-\mu \mathrm{M}$ ubiquitin in 78:20:2 $\mathrm{MeOH}: \mathrm{H}_{2} \mathrm{O}: \mathrm{HOAc}$ flowing at 0.15 $\mu \mathrm{L} / \mathrm{min}$. A small pulse of $\mathrm{N}_{2}\left(\sim 10^{-7}\right.$ torr $)$ was introduced to cool ion axial motion after trapping. A 95-s delay also allowed complete restoration of base pressure before data acquisition. The 5 amol of ubiquitin

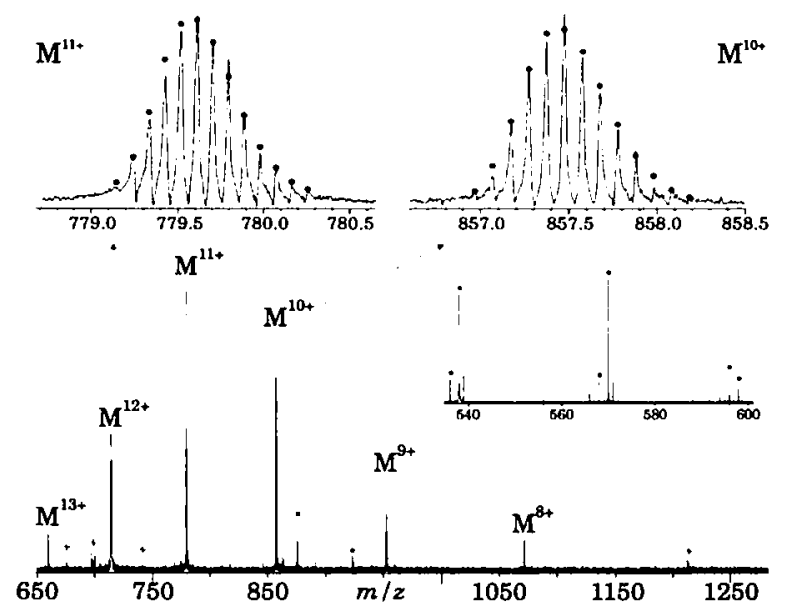

Figure 2. ESI spectrum from injection of $50-\mathrm{fmol}$ ubiquitin $(0.5$ $\mu \mathrm{L}, 100 \mathrm{nM})$ at $1 \mu \mathrm{L} / \mathrm{min}$. , calculated isotopic distribution; $-t$, peaks from noise; $\mathbf{m}$, valve impurities (all $1^{+}$ions).

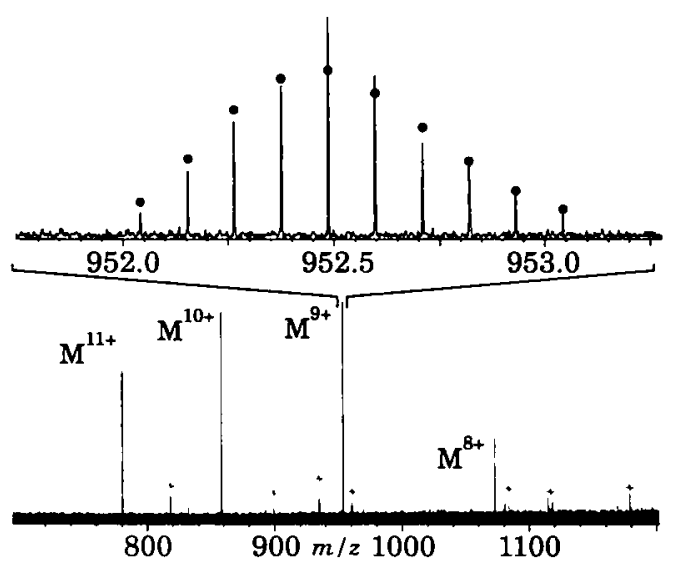

Figure 3. ESI spectrum from constant infusion of $20-\mu \mathrm{M}$ ubiquitin, $0.15 \mu \mathrm{L} / \mathrm{min}$, with $100-\mu \mathrm{s}$ gated trapping of the ions $(5$ attomol consumed). , calculated isotopic distribution; $-\boldsymbol{r}$, noise peaks.

consumed gave (Figure 3) S/N 23:1, with $R P>3 \times$ $10^{5}$.

Thus the microelectrospray techniques of Caprioli and co-workers [9] and of Wilm and Mann [5] coupled with FTMS give promise of $R P>10^{5}$ for complete mass spectra from subfemtomole quantities of large molecules. However, the $0.5-\mu \mathrm{L}$ sample injection described here routinely provides such spectra from $<10^{-13} \mathrm{~mol}$ quantities of submitted samples.

\section{Acknowledgments}

The authors thank Troy D. Wood, Keith L. Goodman, J. Paul Speir, and Russell A. Chorush for helpful discussions and suggestions. We also acknowledge the National Institutes of Health for generous financial support under grant GM-16609.

\section{References}

1. Karas, M.; Hillenkamp, F. Anal. Chem. 1988, 60, 2299-2301.

2. Fenn, J. B.; Mann, M.; Meng, C. K.; Wong, S. F.; Whitehouse, C. M. Mass Spectrom. Rev. 1990, 9, 37-70.

3. Feng, R.; Konishi, Y. Anal. Chem. 1992, 64, 2090-2095.

4. Jespersen, S.; Niessen, W. M. A.; Tjaden, U. R.; van der Greef, J.; Litborn, E.; Lindberg, U.; Roeraade, J. Rapid Commun. Mass. Spectrom. 1994, 8, 581-584.

5. Wilm, M.; Mann, M. 13 th International Mass Spectrometry Conference; Budapest, Hungary, September 1994.

6. Smith, R. D.; Wahl, J. H.; Goodlett D. R.; Hofstadler, S. A. Anal. Chem. 1993, 65, 574A-584A.

7. Hunt, D. F.; Henderson, R. A.; Shabanowitz, J.; Sakaguchi, K.; Michel, H.; Sevilir, N.; Cox, A. L.; Apella, E.; Engelhard, V. H. Science 1992, 255, 1261-1263.

8. Cody, R. B.; Tamura, J.; Finch, J. W.; Musselman, B. D. J. Am. Soc. Mass. Spectrom. 1994, 5, 194-200.

9. Emmett, M. R.; Caprioli, R. M. J. Am. Soc. Mass. Spectrom. 1994, 5, 605-613.

10. Andren, P. E.; Emmett, M. R.; Caprioli, R. M. J. Am. Soc. Mass. Spectrom. 1994, 5, 867-869.

11. Meyer, V. R. Practical High Performance Liquid Chromatography; Wiley: New York, 1988.

12. Hofstadler, S. A.; Wahl, J. H.; Bruce J. E.; Smith, R. D. J. Am. Chem. Soc. 1993, 115, 6983-6984.

13. Beu, S. C.; Senko, M. W.; Quinn, J. P.; Wampler, F. M., III; McLafferty, F. W. J. Am. Soc. Mass. Spectrom. 1993, 4, 557-565. 